Soares, R. \& Maia, L. (2019). Ideias matemáticas na prática de um serralheiro: contexto para o ensino de matemática. Revista Latinoamericana de Etnomatemática, 12(4), 69-83. DOI:

Artículo recibido el 23 de julio de 2019. Aceptado para publicación el 7 de diciembre de 2019

\title{
Ideias matemáticas na prática de um serralheiro: contexto para o ensino de matemática
}

\section{Mathematical ideas in a locksmith's pratice: contexto for teaching mathematics}

\author{
Roberta Luzia Soares de Souza ${ }^{1}$ \\ Lucélida de Fátima Maia da Costa²
}

\begin{abstract}
Resumo
Este trabalho tem incumbência de apresentar os resultados de uma pesquisa que tem como objetivo compreender ideias matemáticas mobilizadas na prática de um serralheiro que podem se constituir contexto para o ensino da matemática escolar. O sujeito da pesquisa é um serralheiro que possui 29 anos de profissão. A pesquisa é do tipo qualitativa com contribuição da pesquisa etnográfica. Para a coleta dos dados foram utilizados a observação, a entrevista e o registro fotográfico. A análise dos dados foi realizada pelo método de triangulação. Os resultados obtidos permitem afirmar que no contexto do serralheiro há uma mobilização de ideias matemáticas nas construções de grades e nos instrumentos de trabalho denominados de gabaritos. Tais ideais têm relação com conteúdos matemáticos ensinados na Educação Básica, tanto no Ensino Fundamental como no Ensino Médio, que podem ser usado pelo professor como contexto para o ensino de matemática.
\end{abstract}

Palavras-chave: Ideias matemáticas; Etnomatemática; Ensino de matemática.

\begin{abstract}
This work is in charge of presenting the results of a research that aims to understand mathematical ideas mobilized in a locksmith's practice that can constitute a context for teaching school mathematics. The research subject is a locksmith with 29 years of experience. The research of a qualitative type with the contribution of ethnographic research. For data colletion, observation, interview and photographic record were used. Data analysis was performed using the triangulation method. The results obtained allow us to affirm that is the constext of the lochsmith there is a mobilization of mathematical ideas in the construction of grids and in the work instruments called templates. Such ideas are related to mathematical content taught in Basic Educacion, both in Elementary and Secondary Educacion, which can be used by the teacher as a context for teaching mathematics.
\end{abstract}

key words: Mathematical ideas; Ethnomathematics; Mathematical teaching.

\section{INTRODUÇÃO}

No contexto escolar, comumente, a matemática é vista pelos alunos como algo complexo e sem relação com a vida real, muitas vezes, por conta da abstração exigida e pela forma como os conteúdos são apresentados em sala de aula.

\footnotetext{
${ }^{1}$ Licenciada em Matemática pela Universidade do Estado do Amazonas-UEA, no Centro de Superiores de Parintins - CESP. Parintins, Brasil, email: robertalpsa@gmail.com

${ }^{2}$ Professora Orientadora. Doutora, Docente do Curso de Matemática da Universidade do Estado do Amazonas - UEA, no Centro de Estudos Superiores de Parintins - CESP. Parintins, Brasil, email: ldfmaiadc@gmail.com
} 
No entanto, sabemos que as ideias matemáticas estão presentes em vários contextos como nas relações de comércio, na fabricação de móveis, no artesanato, na construção de casas entre outras situações, que podem servir de subsídios para o professor apresentar, em sala de aula, uma matemática com mais sentido e significado para seus alunos (Costa, 2012; D’Ambrosio, 2012).

Assim sendo, esse artigo apresenta resultados oriundos de uma pesquisa qualitativa que buscou responder ao seguinte questionamento: quais ideias matemáticas são mobilizadas na prática de um serralheiro que podem se constituir contexto para o ensino da matemática escolar? O qual originou o objetivo geral que é: compreender ideias matemáticas mobilizadas na prática de um serralheiro que podem se constituir contexto para o ensino da matemática escolar.

Esse objetivo foi desmembrado em três objetivos específicos que são: identificar as ideias matemáticas mobilizadas na prática de um serralheiro; verificar os modos de solucionar problemas "matemáticos" no âmbito da prática de um serralheiro; verificar possíveis relações entre as ideias matemáticas mobilizadas na prática de um de serralheiro e conteúdos matemáticos ensinados na escola.

A pesquisa foi desenvolvida em uma serralheria na cidade de Parintins-Amazonas, tendo como sujeito um serralheiro que possui 29 anos de profissão. O critério de seleção do sujeito aconteceu através do fácil contato entre o pesquisador e o sujeito. Nesse texto, o sujeito será identificado com o codinome senhor Bentes e os recortes de suas falas estarão entre aspas e em itálico.

Os procedimentos metodológicos foram elaborados a partir dos princípios da pesquisa qualitativa (Gerhardt e Silveira, 2009), pois nos inserimos na realidade investigada para conhecer e descrever em profundidade aspectos que são relevantes para a compreensão dos sentidos, dos significados, da construção, da divulgação e da validação do conhecimento produzido no contexto da prática do senhor Bentes. Por tratarmos apenas de uma pequena amostra do fenômeno, a pesquisa pode ser entendida como um estudo de caso etnográfico (Gil, 2008), isto porque evidenciamos a compreensão de saberes e fazeres de um único serralheiro, mas que é um representante de um grupo de profissionais culturalmente identificáveis.

Para a construção dos dados utilizamos a observação sistemática, o registro fotográfico e a entrevista semiestruturada. Para a observação nos guiamos pelas ideias de Gerhardt e 
Soares, R. \& Maia, L. (2019). Ideias matemáticas na prática de um serralheiro: contexto para o ensino de matemática. Revista Latinoamericana de Etnomatemática, 12(4), 69-83. DOI:

10.22267/relatem.19124.37

Silveira (2009), que nos permitiu perceber as ideias matemáticas presentes na prática do senhor Bentes e verificarmos os modos como soluciona os problemas "matemáticos" que surgem.

O registro fotográfico foi realizado no decorrer da observação, com a intenção de registrar aspectos de sua prática para posterior análise. Para tanto, fotografamos os instrumentos, a matéria prima, diversas etapas das construções e o produto final.

A entrevista foi realizada com o sujeito da pesquisa e desenvolvida em dois momentos: o primeiro se deu nos diálogos estabelecidos no período das observações, onde foram feitas perguntas no decorrer da realização de seus trabalhos. O segundo momento foi realizado em um dia previamente agendado, momento em que fizemos questionamentos sobre sua prática, com intuito de compreendermos as mobilizações das ideias matemáticas realizadas em sua atividade profissional (Gerhardt e Silveira, 2009).

Para a análise dos dados utilizamos o método de triangulação que é "[...] um procedimento que combina diferentes métodos de coleta e análise de dados [...]" (Zappellini e Feuerschutte, 2015, p. 246), ou seja, nossa compreensão do fenômeno estudado decorre da triangulação das informações obtidas por meio das observações, da entrevista e do registro fotográfico.

Os resultados obtidos são apresentados e discutidos nas três sessões que compõe este artigo, as quais são: os gabaritos; resolução de situações-problemas na prática de um serralheiro; possíveis relações entre as ideias matemáticas do serralheiro e conteúdos matemáticos ensinado na escola.

\section{OS GABARITOS}

Nós, desde a infância, expressamos formas de pensar e resolver situações-problemas que envolvem um pensar lógico-matemático e a construção de conhecimentos "por meio das relações que estabelecemos entre objetos, fenômenos, fatos, processo dedutivo individual, mas que adquire sentido e significação diferentes de acordo ao contexto sociocultural no qual estamos inseridos" (Costa, 2018, p. 15).

Em diferentes contextos, percebemos pensamentos fundamentados em lógicas diferentes que se manifestam no saber/fazer de determinados grupos socioculturais, que direcionam as práticas das pessoas e suas ações com vista à sobrevivência e o convívio em sociedade (D’Ambrosio, 2013). 
Na prática do senhor Bentes, sujeito da pesquisa, percebemos um pensamento lógicomatemático e a mobilização de ideias matemáticas que se manifestam na construção de grades. Entendemos ideias matemáticas como as "habilidades de classificar, ordenar, inferir, generalizar, medir e avaliar" (D’Ambrosio, 2013, p. 30), ações perceptíveis na prática do serralheiro.

No desenvolvimento da pesquisa, buscamos compreender o saber/fazer do senhor Bentes que tem 47 anos de idade e 29 anos de profissão, tem o ensino médio completo e aprendeu a profissão sendo ajudante de um serralheiro, como relata: "Comecei a aprender a profissão com 12 anos de idade. Quem me ensinou foi um vizinho que era serralheiro. Eu ia para serralheria desse vizinho, que ficava ao lado de casa, quando não estava na escola e o ajudava nas construções de grades" (comunicação pessoal, 9 de julho de 2018).

A construção de grades exige conhecimentos específicos como a diferenciação de tipos de ferros (matéria prima), o manuseio de equipamentos de corte e a confecção de instrumentos de medida e modelagem. Dentre os produtos originados pelo serralheiro destacamos a construção dos gabaritos.

No desenvolvimento da pesquisa, os gabaritos analisados foram construídos pelo próprio senhor Bentes no decorrer da sua vida profissional e são utilizados na construção de grades, mais precisamente na determinação do desenho ${ }^{3}$ das grades, como ele próprio relata: "Fiz [os gabaritos] pela necessidade da construção das grades, eles facilitam a construção do desenho da grade" (comunicação pessoal, 9 de julho de 2018), nesse sentido, os gabaritos servem como "moldes" para que o desenho da grade seja construído com as medidas e o formato desejado, como indica o nosso interlocutor: "Os gabaritos me ajudam a dar o formato e a medida igual para a barrinha de ferro" (comunicação pessoal, 9 de julho de 2018).

De acordo com as observações, podemos afirmar que no processo de construção dos gabaritos há uma mobilização de ideias matemáticas, que se traduzem na materialização da estratégia elaborada pelo serralheiro para resolver uma determinada situaçãoproblema. Para Costa (2012, p. 20), a “[...] elaboração de estratégias é um processo que implica na combinação de conhecimentos [...]" diversos e nesse processo as formas de pensar do sujeito refletem aspectos do seu contexto sociocultural.

\footnotetext{
${ }^{3} \mathrm{O}$ sujeito da pesquisa denomina desenho para o traçado das ornamentações das grades.
} 
Soares, R. \& Maia, L. (2019). Ideias matemáticas na prática de um serralheiro: contexto para o ensino de matemática. Revista Latinoamericana de Etnomatemática, 12(4), 69-83. DOI:

Assim, a construção dos gabaritos expressa uma aprendizagem etnomatemática do serralheiro, entendida como uma aprendizagem que decorre da observação do fazer de outros, considerados mais experientes em determinadas práticas desenvolvidas no âmbito de um grupo culturalmente identificável do qual o sujeito faz parte (Costa, 2012).

As aprendizagens do senhor Bentes adquiridas no convívio com outros serralheiros, seus pares, podem ser entendidas a partir da etnomatemática que segundo Vergani (2009, p. 220), incorpora "uma consciência vigilante das diferentes linguagens humanas" e

"traduz-se na sua capacidade vivencial de integrar criativamente as razões da razão e da imaginação, do saber e da emoção, do sucesso profissional e do bem-estar comunitário, do sobressalto e da paz, das práticas concretas e das reflexões teórica que as fundamentam" (Vergani, 2009, p. 220).

As aprendizagens etnomatemáticas do Senhor Bentes lhes permitiram construir o gabarito apresentado na fotografia 1, que foi elaborado para servir de molde na construção de modelos de grades que exigem o formato de semicircunferência.

A função desse gabarito é servir de suporte e molde para o serralheiro dobrar as barrinhas de ferro que serão usadas na construção da grade. Ao analisarmos esse instrumento notamos a concretização de conhecimentos, inclusive matemáticos, que foram mobilizados no seu processo de construção que são fundamentais para o serralheiro definir o comprimento, a espessura e a curvatura da forma.

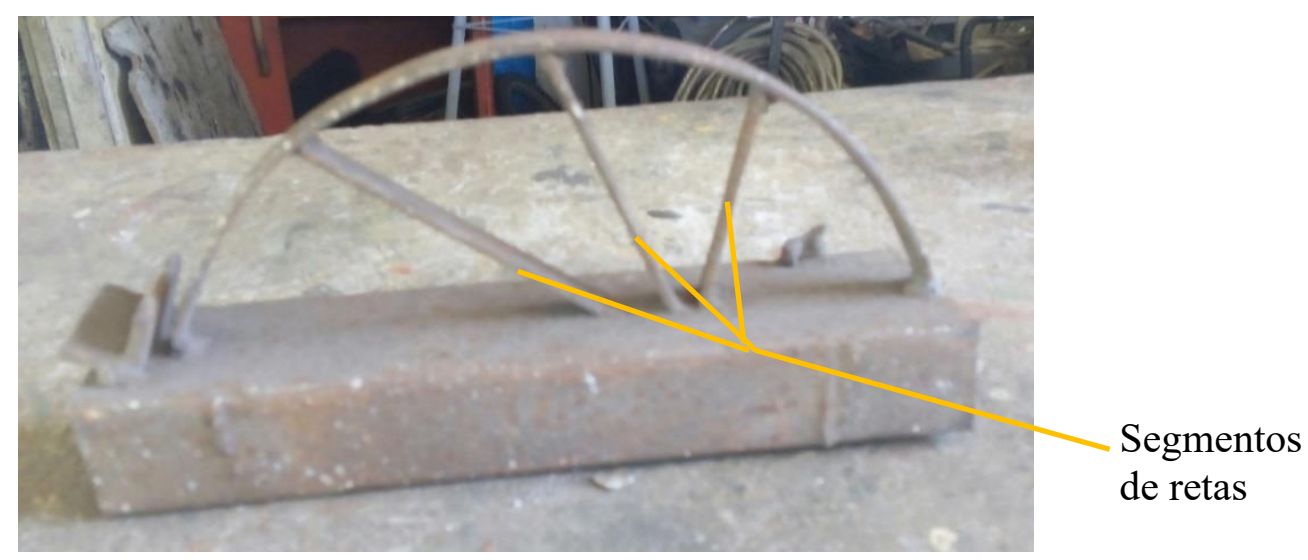

Fotografia 1. Gabarito de semicircunferência Fonte: Roberta Luzia (2018)

Na construção de um gabarito, de acordo com as ideias de D’Ambrosio (2012, p. 19), “[...] o conhecimento é gerado do saber, que vai, por sua vez, ser decisivo para a sua 
ação [...]", ou seja, a ação do serralheiro parte de um saber acumulado e adquirido no convívio com seus pares, o qual é decisivo para a construção das grades encomendadas. No gabarito, percebemos facilmente a presença de uma semicircunferência, elemento geométrico ensinado na Educação Básica. A semicircunferência é a metade de uma circunferência e seu arco corresponde a 180 graus (Almeida, 2007). Na figura 1, podemos visualizar o modelo matemático presente no gabarito.

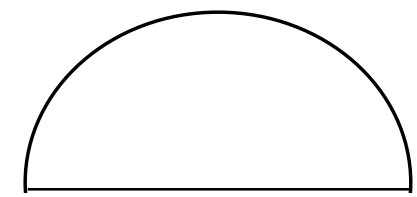

Figura 1. Modelo matemático

Fonte: Organizado por Roberta Luzia (2018)

Como a barrinha de ferro utilizada na construção do gabarito não é tão fácil de dobrar, foi necessário que o senhor Bentes soldasse três pedaços de ferro de comprimentos diferentes em posições estratégicas, isto é, em pontos diferentes para garantir que a barrinha de ferro fizesse a curvatura necessária para formar o arco de 180 graus da semicircunferência, como visualizamos na fotografia 1. Esses pedaços de ferro podem ser vistos como segmentos de reta que dão sustentação para o gabarito suportar o peso da barrinha de ferro ao ser dobrada.

O uso do gabarito assegura que as semicircunferências produzidas para o desenho da grade tenham medidas iguais, isto é, o mesmo raio, diâmetro e comprimento. $\mathrm{Na}$ fotografia abaixo podemos visualizar a grade já pronta cujo traçado ornamental foi produzido pelo gabarito.

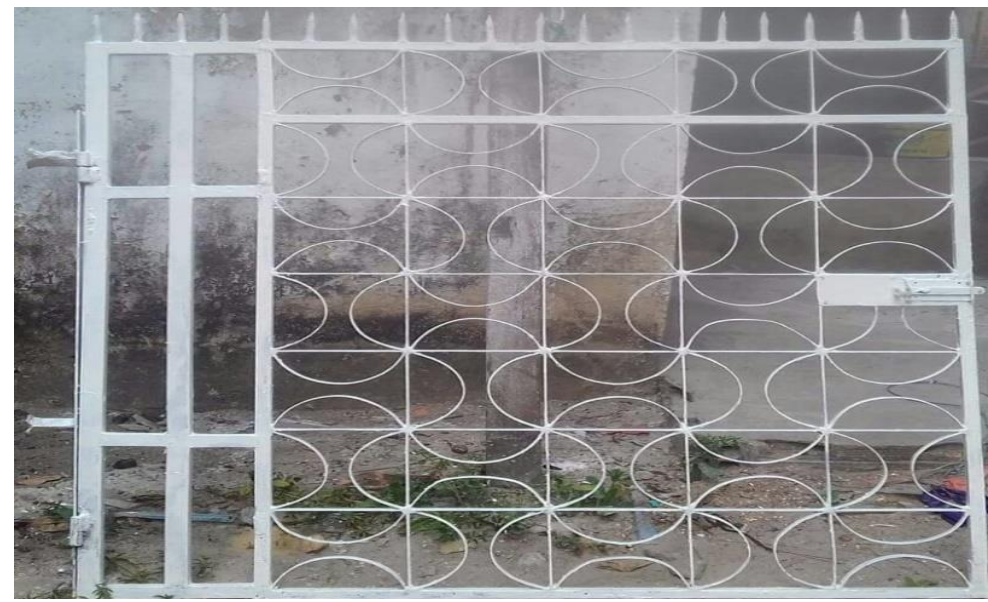

Fotografia 2. Grade construída com a ajuda do gabarito Fonte: Roberta Luzia (2018) 
Soares, R. \& Maia, L. (2019). Ideias matemáticas na prática de um serralheiro: contexto para o ensino de matemática. Revista Latinoamericana de Etnomatemática, 12(4), 69-83. DOI:

10.22267/relatem.19124.37

Ao medirmos o raio e o diâmetro das semicircunferências da grade obtemos $6,5 \mathrm{~cm}$ e 13 $\mathrm{cm}$ respectivamente, ao medir o raio e o diâmetro da semicircunferência do gabarito obtivemos as mesmas medidas, isso nos mostra a precisão que o gabarito tem em assegurar medidas iguais para todas as semicircunferências da grade.

Para sabermos o comprimento das semicircunferências da grade, e consequentemente o comprimento da semicircunferência do gabarito, basta pegarmos o comprimento da circunferência que é dado por $\mathrm{C}=2 \pi \mathrm{r}$ (duas vezes o pi vezes o raio), sendo que a semicircunferência é metade de uma circunferência, logo o comprimento da semicircunferência será a metade do comprimento da circunferência, assim veremos que o comprimento do arco da semicircunferência é dado por $\mathrm{C} / 2=\pi \mathrm{r}$ (pi vezes o raio) onde o $\pi$ é aproximadamente 3,14 (Almeida, 2007), fazendo os devidos cálculos obtemos 20,41 cm de comprimento, sendo assim, para construir cada arco da semicircunferência o senhor Bentes necessita 20,41 cm de ferro.

Os gabaritos construídos pelo senhor Bentes variam de acordo com o desenho da grade a ser construída. Ao depender de cada padrão estético solicitado é possível identificarmos a presença de diferentes objetos matemáticos na composição dos gabaritos, isto demonstra a variabilidade das ideias matemáticas que são mobilizadas na prática de um serralheiro.

$\mathrm{Na}$ fotografia 3, podemos visualizar mais um gabarito construído pelo senhor Bentes para ser utilizado no desenho de uma grade.

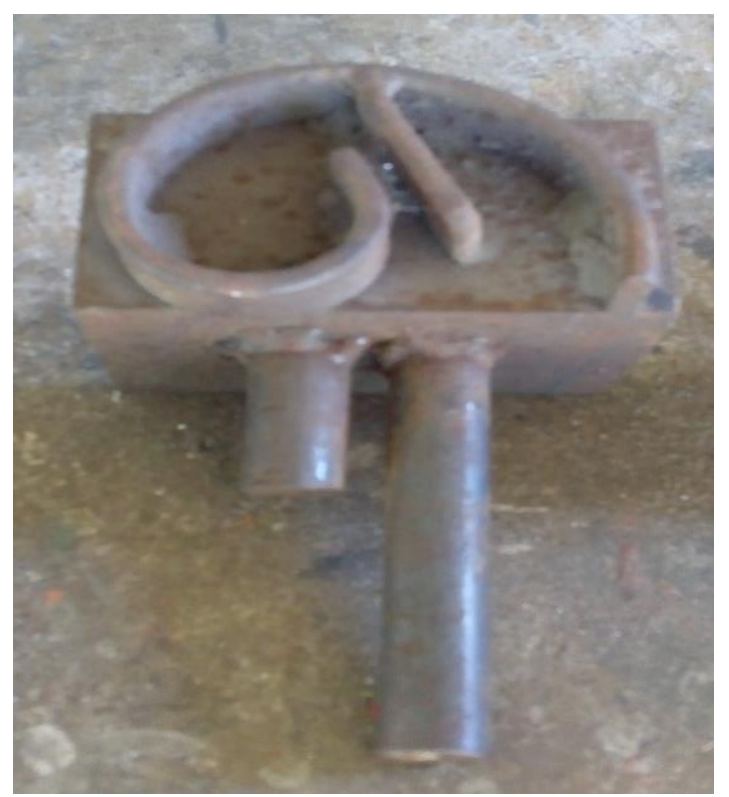

Fotografia 3. Gabarito de curva

Fonte: Roberta Luzia (2018) 
Esse gabarito serve para dobrar as pontas das barrinhas de ferro. Ao analisarmos o formato das pontas dobradas, identificamos a presença de uma curva aberta simples, elemento geométrico ensinado na Educação Básica. A curva é uma trajetória seguida por um ponto que se move de acordo com uma lei (Almeida, 2007).

No desenvolvimento da pesquisa o gabarito da fotografia 3, foi utilizado na construção de uma grade de ornamentação mais complexa, pois requeria a combinação de dois gabaritos para a construção do desenho solicitado pelo cliente.

Para a construção da grade vista na fotografia 4, o senhor Bentes usou os dois gabaritos vistos nas fotografias 1 e 3, combinando assim a semicircunferência com a curva aberta. $\mathrm{Na}$ fotografia 4, podemos visualizar o traçado ornamental que resultou dessa combinação.

Ponto de encontro dos gabaritos

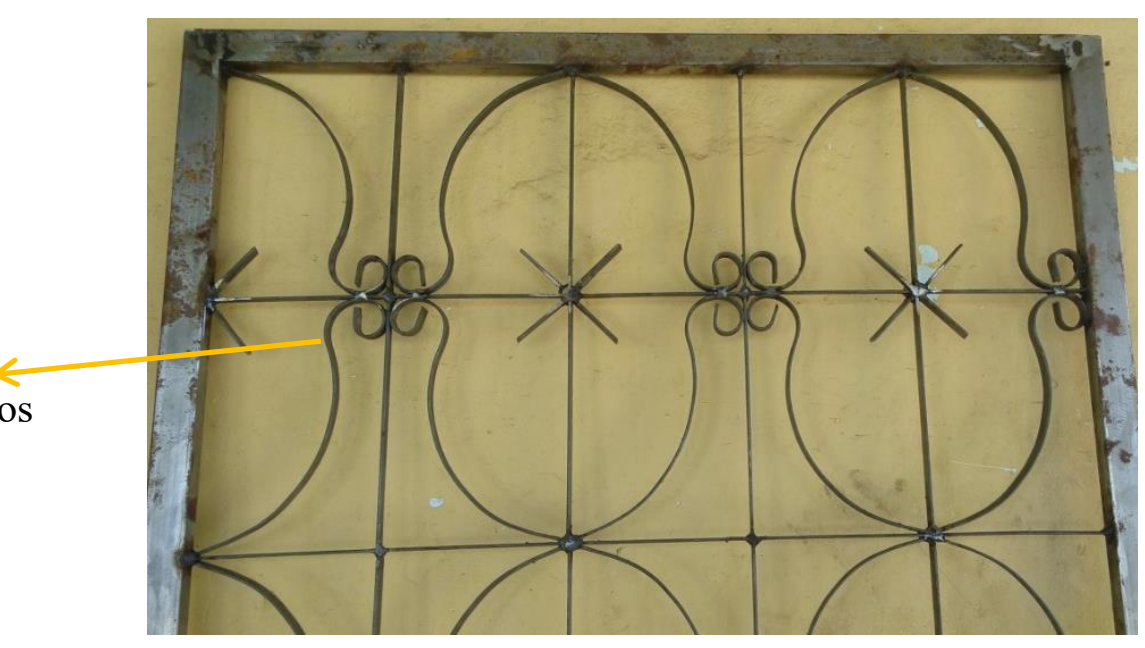

Fotografia 4. Grade construída com a combinação dos gabaritos Fonte: Roberta Luzia (2018)

A combinação de um gabarito com o outro gera um terceiro elemento que reúne as características dos dois gabaritos. Esse processo de combinação dos gabaritos de acordo com as ideias de D’Ambrosio (2012) é a consciência do saber/fazer do serralheiro em ação, pois para combinar os gabaritos o serralheiro busca conhecimentos acumulados adquiridos, muitas vezes com seus pares e ao longo da sua vida profissional que são determinantes para a construção do terceiro elemento.

As ideias matemáticas são mobilizadas pelo senhor Bentes para resolver diversas situações-problemas que se apresentam na construção das grades.

\section{RESOLUÇÃO DE SITUAÇÕES-PROBLEMAS NA PRÁTICA DE UM SERRALHEIRO}


Soares, R. \& Maia, L. (2019). Ideias matemáticas na prática de um serralheiro: contexto para o ensino de matemática. Revista Latinoamericana de Etnomatemática, 12(4), 69-83. DOI:

A vida em sociedade nos leva a enfrentar situações-problemas que exigem diversos conhecimentos para solucioná-los. Assim, “[...] em todas as culturas e em todos os tempos, o conhecimento, que é gerado pela necessidade de repostas a problemas e situações distintas, está subordinado a um contexto natural, social e cultural" (D’Ambrosio, 2013, p. 60).

Os conhecimentos, inclusive matemáticos, adquiridos pelo homem ao longo de sua história, são constituídos de saberes e fazeres práticos desenvolvidos pela capacidade de analisar uma situação-problema (Costa, 2012).

"o modo como enfrentamos a situação-problema, escolhemos as ferramentas e elaboramos as estratégias em busca de uma solução expressa conhecimentos construídos no meio social e traz características culturais que podem influenciar nos significados que emergem do contexto no qual a situação se apresenta" (Costa, Mafra e Verdial, 2015, p. 4).

Desse modo, as situações-problemas ganham sentido e significado de acordo com o contexto sociocultural no qual se apresenta, assim, as crenças, os valores e a formas de pensar culturalmente influência a maneira se posicionar diante de tais situações (Costa, 2012). As estratégias utilizadas para resolvê-las expressam saberes e fazeres construídos em seu dia a dia e com o convívio de seus pares.

No contexto sociocultural do senhor Bentes, notamos diversas situações-problemas que se apresentam nas construções de grades e que eram resolvidos através da elaboração de instrumentos que o auxiliam na resolução da situação.

Uma das situações problemas enfrentados pelo senhor Bentes que observamos durante desenvolvimento da pesquisa se refere à necessidade de soldar uma chapa de ferro ondulada na metade da largura de uma barra de ferro, como podemos visualizar na fotografia 4 .

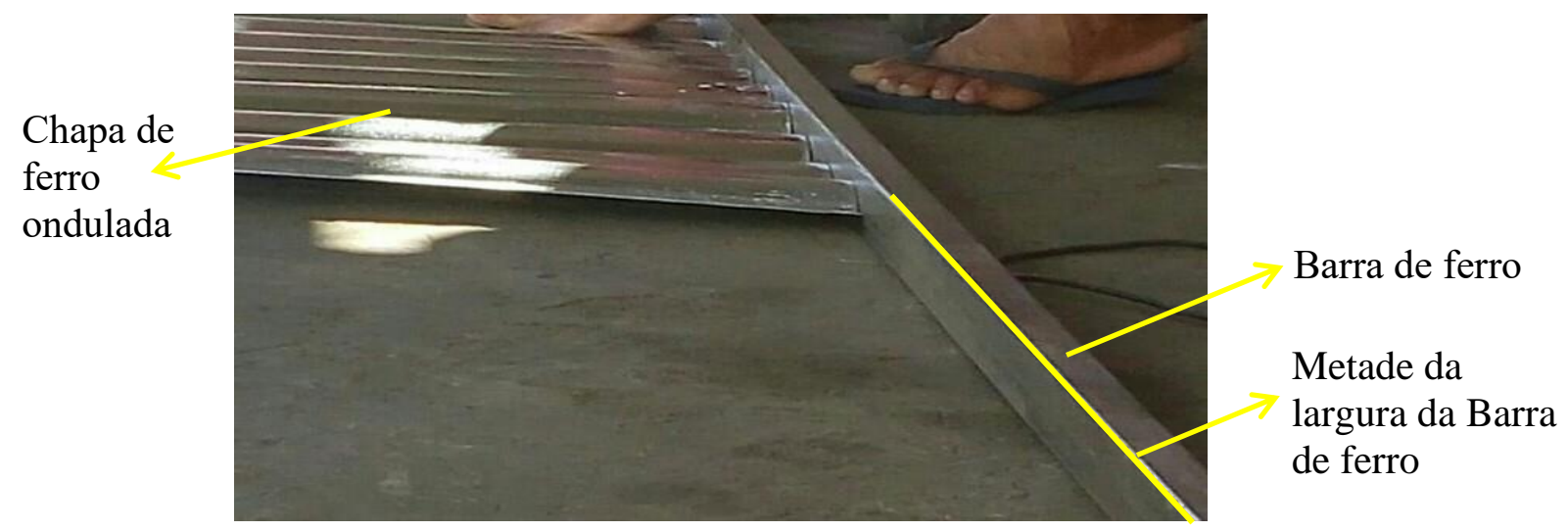

Fotografia 4. Situação problema

Fonte: Roberta Luzia (2018) 
A chapa de ferro ondulada tem que ser soldada na metade da largura de uma barra de ferro, cujas dimensões são $3 \mathrm{~cm}$ de largura, $2 \mathrm{~cm}$ de altura e $210 \mathrm{~cm}$ de comprimento, assim, a chapa de ferro ondulada tem que ser soldada exatamente a $1,5 \mathrm{~cm}$ na largura da barra de ferro em toda sua extensão.

Para resolver essa situação o senhor Bentes construiu um gabarito. Esse instrumento tinha a função de sustentar a chapa ondulada na metade da largura da barra de ferro para poder realizar a soldagem.

$\mathrm{Na}$ fotografia 5, podemos visualizar o gabarito construído pelo senhor Bentes para resolver a situação-problema.

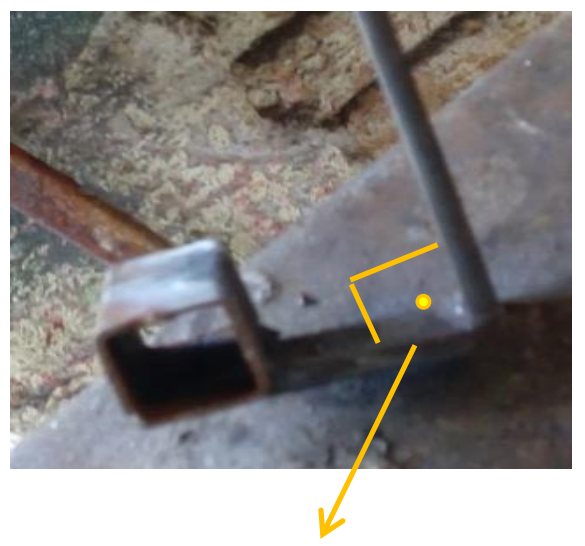

Ângulo de 90 graus

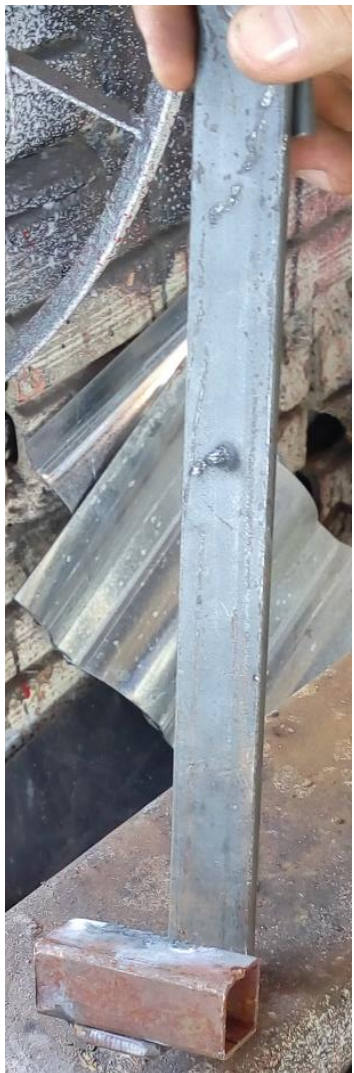

Fotografia 5. O gabarito construído Fonte: Roberta Luzia (2018)

Esse gabarito foi construído a partir de um pedaço de uma barrinha de ferro cuja extremidade foi dobrada formando um ângulo de 90 graus. Podemos perceber que na ponta tem um pedaço de ferro soldado cuja altura é $1,5 \mathrm{~cm}$, exatamente a altura necessária para sustentar a chapa ondulada durante a soldagem.

Todo esse processo evidencia a forma como o serralheiro entendeu a situação-problema, a estratégia que ele elaborou (construção do gabarito), a utilização da estratégia 
Soares, R. \& Maia, L. (2019). Ideias matemáticas na prática de um serralheiro: contexto para o ensino de matemática. Revista Latinoamericana de Etnomatemática, 12(4), 69-83. DOI:

elaborada (uso do gabarito) e a avaliação da solução encontrada, pois durante todo o trabalho, principalmente, no produto final, o serralheiro verificou se a chapa estava soldada no lugar certo e se o portão construído apresentava alguma falha ou deformação. Nesse processo, as etapas desenvolvidas pelo serralheiro se assemelham as indicadas por Polya (1995) para a resolução de problemas.

Na construção do gabarito percebemos que há mobilização de ideias matemáticas que se manifestam nas ações do serralheiro em classificar, medir, avaliar e generalizar. Tais ideias têm relação com conteúdos matemáticos ensinados na escola, consequentemente, podem servir de contexto para o ensino de matemática.

\section{POSSÍVEIS RELAÇÕES ENTRE AS IDEIAS MATEMÁtiCAS DO SERRALHEIRO E CONTEÚDOS MATEMÁTICOS ENSINADO NA ESCOLA}

A partir da identificação das ideias matemáticas que o serralheiro mobiliza no desenvolvimento do seu trabalho, desde a elaboração do orçamento até a finalização da construção das grades, é possível estabelecermos uma relação entre tais ideias e conteúdos matemáticos ensinados na Educação Básica, tanto no Ensino Fundamental, como no Ensino Médio. Essas ideias matemáticas se forem discutidas no ambiente escolar, podem ser usadas como referência para ensino de diversos conteúdos matemáticos.

\begin{tabular}{|c|c|c|}
\hline Ideias mobilizadas & Conteúdo escolar & Nível de ensinar \\
\hline Elaboração do orçamento & $\begin{array}{l}\text { Unidades de medidas } \\
\text { (comprimento); quatro } \\
\text { operações básicas (adição, } \\
\text { subtração, multiplicação e } \\
\text { divisão); proporção; } \\
\text { Matemática financeira. }\end{array}$ & $\begin{array}{l}\text { Ensino Fundamental } \\
\left(5^{\circ} \text { ano; } 6^{\circ} \text { ano e } 9^{\circ} \text { ano }\right) \\
\text { Ensino Médio } \\
\left(1^{\circ} \text { ano e } 3^{\circ} \text { ano }\right)\end{array}$ \\
\hline $\begin{array}{l}\text { Cálculo do valor das } \\
\text { grades }\end{array}$ & $\begin{array}{l}\text { Unidades de medidas } \\
\text { (comprimento); } \\
\text { multiplicação; regra de três } \\
\text { simples; cálculo de área } \\
\text { (retângulo e quadrado). }\end{array}$ & $\begin{array}{l}\text { Ensino Fundamental } \\
\left(5^{\circ} \text { ano; } 6^{\circ} \text { ano e } 9^{\circ} \text { ano }\right) \\
\text { Ensino Médio } \\
\left(1^{\circ} \text { ano e } 2^{\circ} \text { ano }\right)\end{array}$ \\
\hline Construção dos gabaritos & $\begin{array}{l}\text { Unidades de medidas } \\
\text { (comprimento); formas } \\
\text { geométricas } \\
\text { (semicircunferência, curvas } \\
\text { abertas); ângulos; }\end{array}$ & $\begin{array}{l}\text { Ensino Fundamental } \\
\left(5^{\circ} \text { ano, } 6^{\circ} \text { ano e } 9^{\circ} \text { ano }\right) \\
\text { Ensino Médio } \\
\left(1^{\circ} \text { ano, } 2^{\circ} \text { ano e } 3^{\circ} \text { ano }\right)\end{array}$ \\
\hline
\end{tabular}




\begin{tabular}{l|l|l}
\hline & segmentos de retas. & \\
\hline Construção das grades & $\begin{array}{l}\text { Unidades de medidas } \\
\text { (comprimento); proporção; }\end{array}$ & $\begin{array}{l}\text { Ensino Fundamental } \\
\left(5^{\circ} \text { ano, 6 } 6^{\circ} \text { ano e } 9^{\circ} \text { ano }\right)\end{array}$ \\
& $\begin{array}{l}\text { divisão; multiplicação; } \\
\text { Cálculo de área (retângulo e } \\
\text { Euadrado); Formas } \\
\text { Euno Médio } \\
\text { geométricas (retângulo e } \\
\text { quadrado). }\end{array}$ & \\
\hline
\end{tabular}

Tabela 1. Relação entre as ideias mobilizadas na construção de grades e conteúdos ensinados na escola

Fonte: Dados empíricos da pesquisa.

O ensino de matemática exige cada vez mais conteúdos que tenham sentido e significado para o aluno, tendo em vista isso, o professor que ensina matemática deve buscar relacionar os conteúdos matemáticos com a realidade, um dos modos é evidenciar ideias matemáticas mobilizadas em diversos contextos reais ou imaginários. Dessa forma, a formação do professor de matemática deve conhecer e reconhecer os saberes e fazeres construídos nos diversos contextos culturais, e até mesmo os saberes e fazeres construídos pelo aluno no seu dia a dia, pois esse saber/fazer pode ser utilizado pelo professor como estratégia de ensino.

O professor que ensina matemática deve desenvolver uma docência que contemple ideias matemáticas presentes em diversos contextos culturais como, por exemplo, na prática de um serralheiro. No desenvolvimento da pesquisa, encontramos a mobilização de ideias matemáticas na construção de grades que se manifestam na forma de medir, calcular, avaliar, ordenar e generalizar.

O saber/fazer matemático encontrado na prática de um serralheiro pode ser entendido a partir da etnomatemática. Pois, a etnomatemática busca a socialização de saberes e fazeres matemáticos adquiridos pelo homem em seu contexto sociocultural, buscando resgatar os conhecimentos construídos e repassados de geração a geração (D’Ambrosio, 2013).

A matemática ensinada pela perspectiva da etnomatemática propicia uma aprendizagem por meio de situações-problemas reais presentes no contexto social e cultural, valorizando os diferentes saberes e fazeres matemáticos encontrados em múltiplos contextos como o saber/fazer matemático de um serralheiro.

Utilizar o saber/fazer matemático construído em um determinado contexto cultural como referência para ensinar matemática, é mostrar para o aluno à matemática como 
Soares, R. \& Maia, L. (2019). Ideias matemáticas na prática de um serralheiro: contexto para o ensino de matemática. Revista Latinoamericana de Etnomatemática, 12(4), 69-83. DOI:

atividade humana (Shliemann, Carraher e Carraher, 2003), permitindo assim que o aluno perceba-a como algo presente na realidade.

As ideias matemáticas mobilizadas na prática do senhor Bentes tem relação com conteúdos matemáticos ensinados na Educação Básica, assim, o professor de matemática pode discuti-las, dentro da sala de aula, como contexto para ensinar diversos conteúdos matemáticos como regra de três simples, cálculo de área (retângulo e quadrado), as quatro operações básicas (adição, subtração, multiplicação e divisão) e entre outros conteúdos que podem ser vistos na tabela 1 , buscando despertar no aluno o interesse em aprender a matemática.

Desse modo, as estratégias de ensino no ambiente escolar e o processo de formação de professor que ensina matemática deve contemplar, também, o aprender no convívio social, pois, a matemática está presente dentro e fora da escola (Shliemann, Carraher e Carraher, 2003), e considerar os conhecimentos matemáticos presente na cultura do aluno e em diversos grupos socioculturais.

\section{CONSIDERAÇÕES FINAIS}

$\mathrm{Na}$ prática do senhor Bentes, encontramos a mobilização de ideias matemáticas expressas no modo que ele mede, compara e elabora estratégias para resolver situaçõesproblemas próprias da sua prática profissional. Essas ideias matemáticas se tornam visíveis nos instrumentos que confecciona para auxiliá-lo na construção das grades, os gabaritos.

Os gabaritos são assim, a materialização de um conhecimento matemático presente no saber/fazer do senhor Bentes que foi adquirido/construído a partir de sua vivência em um grupo culturalmente identificável, os serralheiros. De modo que, implicitamente, estão impressos valores, percepções, entendimentos e saberes que são repassados de geração a geração por meio da observação e da oralidade.

As ideias matemáticas mobilizadas pelo senhor Bentes na construção de grades, desde a elaboração do orçamento até a finalização da construção das grades, têm relação com os conteúdos matemáticos ensinado no Ensino Fundamental e no Ensino Médio, que podem ser usadas pelo professor como contexto para ensinar diversos conteúdos matemáticos. 
Os resultados desta pesquisa podem contribuir para o desenvolvimento da Educação Matemática na cidade de Parintins, pois apresenta modos de fazer e pensar matemática enraizada culturalmente, podendo assim subsidiar novas pesquisas sobre conhecimentos matemáticos presentes em diferentes contextos culturais que podem, inclusive, dar sentido e significado aos objetos matemáticos ensinados e aprendidos na escola.

\section{REFERÊNCIAS}

Almeida, D. G. (2007). Matemática. Universidade do Estado do Amazonas - Parformar. Manaus: UEA edições.

Costa, L. F. M. (2012). A etnomatemática na educação do campo, em contexto indígena e ribeirinha, seus processos cognitivos e implicações à formação do professor (Dissertação de Mestrado). Universidade do Estado do Amazonas, Manaus.

Costa, L. F. M., Mafra, J. R., \& Verdial, L. (2015). Resolver problemas: uma aprendizagem cultural. In: XV Conferência Interamericana de Educação Matemática - CIAEM, 15, 2015, Tuxtla Gutierrez - Mexico. Anais... Tuxtla Gutierrez - Mexico, 1-9.

Costa, L. F. M. (2018). Metodología do ensino da matemática: Fragmentos possíveis. Manaus: BK Editora.

D’Ambrosio, U. (2012). Educação matemática: da teoría à prática. Coleção perspectiva em educação matemática. Campinas, SP: Papirus.

D’Ambrosio, U. (2013). Etnomatemática: elo entre as tradições e a modernidade. Coleção tendências matemáticas. Belo Horizonte: Autêntica editora.

Gil, A. C. (2008). Métodos e técnicas de pesquisa social. São Paulo: Altas.

Gerhardt, T. E., \& Silveira, D. T. (Orgs.) (2009). Métodos de pesquisa. Coordenado pela Universidade Aberta do Brasil - UAB/UFRGS e pelo Curso de Graduação Tecnológica - Planejamento e Gestão para o Desenvolvimento Rural da SEAD/UFRGS. Porto Alegre: Editora da UFRGS.

Polya, G. A. (1995). A arte de resolver problemas: um novo aspecto do método matemático. Rio de Janeiro: Interciência.

Shliemann, A. D; Carraher, D. W; \& Carraher, T. N. (2003). Na vida dez, na escolar zero. São Paulo: Cortez.

Vergani, T. (2009). A criatividade como destino: transdisciplinaridade, cultura e educação. São Paulo: Livraria da Física. 
Soares, R. \& Maia, L. (2019). Ideias matemáticas na prática de um serralheiro: contexto para o ensino de matemática. Revista Latinoamericana de Etnomatemática, 12(4), 69-83. DOI:

10.22267/relatem.19124.37

Zappellini, M. B., \& Feuerschutte, S. G. (2015). O uso da triangulação na pesquisa científica brasileira em administração (v.6, $\mathrm{n}^{\circ} 2$ ). Revista de administração: ensino e pesquisa. Rio de Janeiro, 246-247. 